\title{
Pro-oncogenic role of SerpinB3 in hepatocellular carcinoma
}

\author{
Andrea Martini, Patrizia Pontisso \\ Department of Medicine, University of Padua, Padua 35128, Italy. \\ Correspondence to: Prof. Patrizia Pontisso, Department of Medicine, University of Padua, Via Giustiniani 2, Padua 35128, Italy. \\ E-mail: patrizia@unipd.it
}

How to cite this article: Martini A, Pontisso P. Pro-oncogenic role of SerpinB3 in hepatocellular carcinoma. Hepatoma Res 2018;4:28. http://dx.doi.org/10.20517/2394-5079.2018.50

Received: 4 May 2018 First Decision: 22 May 2018 Revised: 6 Jun 2018 Accepted: 7 Jun 2018 Published: 29 Jun 2018

Science Editor: Guang-Wen Cao Copy Editor: Jun-Yao Li Production Editor: Cai-Hong Wang

\begin{abstract}
Hepatocellular carcinoma (HCC) is one of the most relevant sanitary problems for its prevalence and poor prognosis. This tumor is characterized by highly heterogeneous features, both at clinical and molecular level. SerpinB3 (squamous cell carcinoma antigen-1 or SCCA1) is a serine-protease inhibitor that protects cells from oxidative stress conditions, but in chronic liver damage it may lead to HCC through different strategies, including inhibition of apoptosis, induction of epithelial to mesenchymal transition, cell proliferation and invasiveness. Mechanisms of tumor growth promotion induced by SerpinB3 encompass the inhibition of intratumor infiltration of natural killer cells and the up-regulation of Myc oncogene. Recently this serpin has also been identified as a Ras-responsive factor and modulator of metabolic pathways. In the liver SerpinB3 is undetectable in normal hepatocytes, but its expression progressively increases in chronic liver diseases, dysplastic nodules and hepatocellular carcinoma, especially in those with poor prognosis, in which it could also exert immunomodulatory effects. In serum SerpinB3/4 isoforms (or SCCA) circulate bound to IgMs (SCCA-IgM) in patients with HCC, and in patients with cirrhosis their levels have been found correlated to the risk of HCC development. Preliminary findings in patients with HCC revealed that SCCA-IgM levels are predictive of HCC prognosis.
\end{abstract}

Keywords: SerpinB3, chronic liver disease, hepatocellular carcinoma, chronic inflammation, SCCA-IgM

\section{INTRODUCTION}

Hepatocellular carcinoma (HCC) is the most frequent primary liver cancer and is ranked as the sixth most common neoplasm and the third leading cause of cancer death worldwide. This liver tumor has been recognised as a leading cause of death among patients with cirrhosis and its incidence is expected to increase in the next

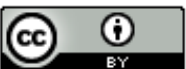

(C) The Author(s) 2018. Open Access This article is licensed under a Creative Commons Attribution 4.0 International License (https://creativecommons.org/licenses/by/4.0/), which permits unrestricted use, sharing, adaptation, distribution and reproduction in any medium or format, for any purpose, even commercially, as long as you give appropriate credit to the original author(s) and the source, provide a link to the Creative Commons license, and indicate if changes were made. 
future $^{[1]}$. This increase in incidence, despite the control of hepatitis B virus and hepatitis $C$ virus infections by vaccination and treatments, is expected by the rising levels of obesity and its metabolic complications ${ }^{[2]}$.

Despite intensive surveillance programs, considerable recent therapeutic advances and the use of potentially radical treatments, clinical outcome of HCC remains still poor, with the majority of patients presenting with advanced disease not eligible for curative therapy ${ }^{[3]}$. These treatments are indeed applicable only for early stage tumors and include resection, liver transplantation and percutaneous ablation, while transarterial chemoembolization (TACE) and sorafenib are regarded as non-curative treatments, able to improve survival in intermediate and advanced stages, respectively ${ }^{[1]}$. The identification of novel therapeutic targets is limited by the well-known intra-nodule and inter-nodule tumour heterogeneity and heterogeneity in tumour evolution ${ }^{[4]}$. It is known indeed the each HCC is composed of a unique combination of somatic alterations, including genetic, epigenetic, transcriptomic and metabolic events that form its unique molecular fingerprint ${ }^{[4]}$. The biological characteristics of the tumor are also enriched by the presence of a frequent underlying chronic liver disease that leads to a persistent exposure to chronic inflammation and oxidative stress by cirrhotic hepatocytes ${ }^{[4]}$. In parallel to this pathological heterogeneity, gene expression profiling has allowed the establishment of several HCC transcriptomic classifications ${ }^{[5-7]}$. One of these recently identified molecular subclasses ( $\mathrm{S} 1$ ) of HCC, associated with poor prognosis, is characterized by aberrant activation of Wnt signaling and transforming growth factor-beta activation ${ }^{[6]}$. This peculiar S1 signature is characterized by overexpression of genes associated to epithelial-to-mesenchymal transition (EMT), a process originally described for embryo development and now believed to be involved in tumor invasion and metastasis and known to be regulated by TGF-beta in $\mathrm{HCC}^{[6]}$. It is interesting to note that high levels of SerpinB3 expression were identified recently only in this subclass ${ }^{[8]}$.

\section{PHYSIOLOGICAL CHARACTERISTICS AND BIOLOGICAL FUNCTIONS OF SERPINB3}

SerpinB3 (formerly known as squamous cell carcinoma antigen-1 or SCCA1) is a member of the family of serine-protease inhibitors (SERPINS). SerpinB3 and its highly homologous isoform SerpinB4 (formerly known as squamous cell carcinoma antigen-2 or SCCA2) were originally purified from a squamous cell carcinoma of the uterine cervix ${ }^{[0]}$. They are encoded by two separate genes located on chromosome 18q21.3, which share a high degree of homology (up to $98 \%$ ). The two encoded glycoproteins have a molecular weight of $45 \mathrm{kDa}$ and are composed by 390 amino acids with up to $92 \%$ similar composition ${ }^{[10]}$. SerpinB3 and SerpinB4 show distinct properties and substrate specificities: the former inhibits papain-like cysteine proteases $^{[11]}$, whereas the latter inhibits both serine and cysteine proteases ${ }^{[12]}$. The specific function or target depends mainly on the variety of the reactive-site loop (RSL), in which only 7 out of 13 amino acid residues (54\%) are identical, and this reactive site is involved in the interaction with the protease, its recognition, and cleavage, resulting in its inhibition ${ }^{[13]}$. SERPINB3/B4 are localized predominantly in the cytosol, however, they have also been detected in other subcellular compartments including lysosomes, mitochondria, the nucleus, and may function extracellularly ${ }^{[10]}$. The localization of SerpinB3/B4 in the nucleus probably depends on physiological state of the cell. While these isoforms are detectable only in the cytoplasm at basal state in cell lines, they have been found in the nucleus in response to UV irradiation. In addition, in clinical samples, nuclear localization of SerpinB3/B4 has been commonly reported in various types of cancers, in psoriasis and in idiopathic pulmonary fibrosis ${ }^{[10]}$.

Regarding their tissue expression, SerpinB3/B4 are physiologically expressed in the basal and parabasal layers of normal squamous epithelium ${ }^{[14]}$, and they are overexpressed in neoplastic cells of epithelial origin $^{[15,16]}$. These proteins are frequently co-expressed in other organs, such as bladder, uterus, esophagus, lung, prostate, testis, thymus, and trachea, but the biological significance of SerpinB3/B4 in normal tissue development and function remains largely unknown $\mathrm{n}^{[10]}$. 


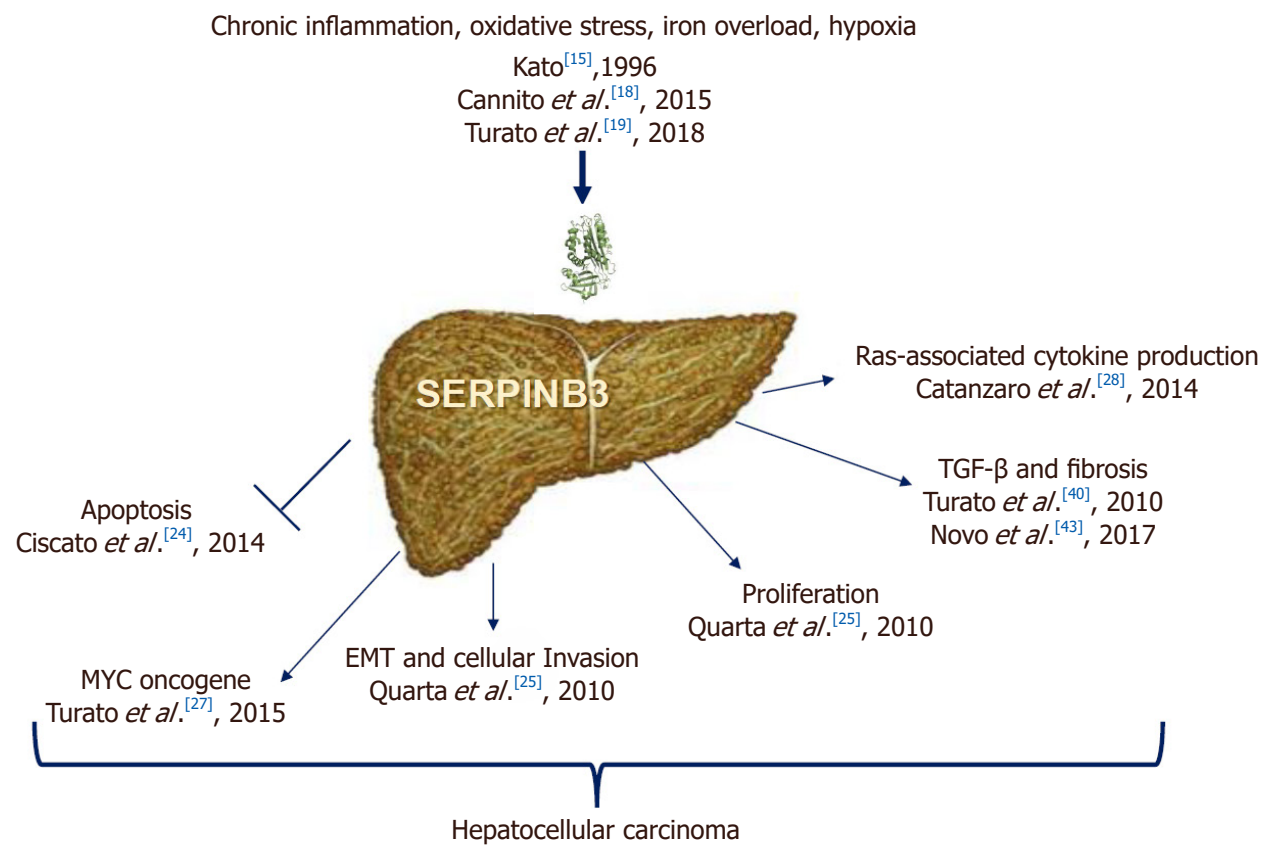

Figure 1. Schematic rapresentation of factors involved in SerpinB3 induction and its pro-oncogenic properties described in the literature

\section{SERPINB3 AND PRIMARY LIVER CANCER \\ Pro-oncogenic potential of SerpinB3}

In recent years several data revealed new biological properties of SerpinB3 in the field of liver carcinogenesis [Figure 1]. The mechanisms that could lead to a dysregulation of SerpinB3 during hepatocarcinogenesis are still largely unknown. Initial studies indicate that this molecule can be upregulated by inflammatory cytokines, namely tumor necrosis factor-alpha, as anti-apoptotic cell death response ${ }^{[17]}$. A novel mechanism involves a selective binding of HIF-2 $\alpha$ to SERPINB3 promoter ${ }^{[18]}$, induced by hypoxic and oxidative stress conditions, like iron overload ${ }^{[18,19]}$. Somatic mutations affecting SerpinB3 repressor(s) cannot be excluded, however, further studies are required to explore this hypothesis.

\section{Anti-apoptotic properties}

Initial studies indicate that SerpinB3 has an anti-apoptotic effect, since in cancer cells it was found to confer resistance to drug-induced apoptosis by inhibiting lysosomal cathepsin proteases ${ }^{[20]}$ and consequent inhibition of the release of mitochondrial cytochrome c.

This serpin also displays a protective role under a variety of stress conditions, with an anti-apoptotic function unrelated to its proteinase inhibition activity ${ }^{[21]}$. Indeed, SerpinB3 protects cells from exposure to radiation through an inhibitory effect either on the MAP family kinase JNK ${ }^{[22]}$ or $\mathrm{p} 38^{[23]}$. More recent findings have demonstrated a novel mechanism of action of SerpinB3, which could contribute to tumor cell resistance to anti-neoplastic drugs. This molecule was found located in the inner mitochondrial compartments, where its binding to the respiratory complex I protected cells from the toxicity of chemotherapeutic agents with a prooxidant action such as doxorubicin and cisplatin ${ }^{[24]}$. This serpin reduced ROS generation induced by these compounds, a crucial step responsible for the opening of the mitochondrial permeability transition pore, shielding tumor cells from apoptotic death ${ }^{[24]}$.

\section{Induction of epithelial-to-mesenchymal transition and cell proliferation}

SerpinB3 induces cell proliferation (increasing $\beta$-catenin expression) and deregulation of adhesion processes as down regulation of E-cadherin and decrease of desmosomal junctions, leading to epithelial-to-mesenchymal transition (EMT) with increased cell invasiveness potential ${ }^{[25]}$. Experimental studies have also reported that 


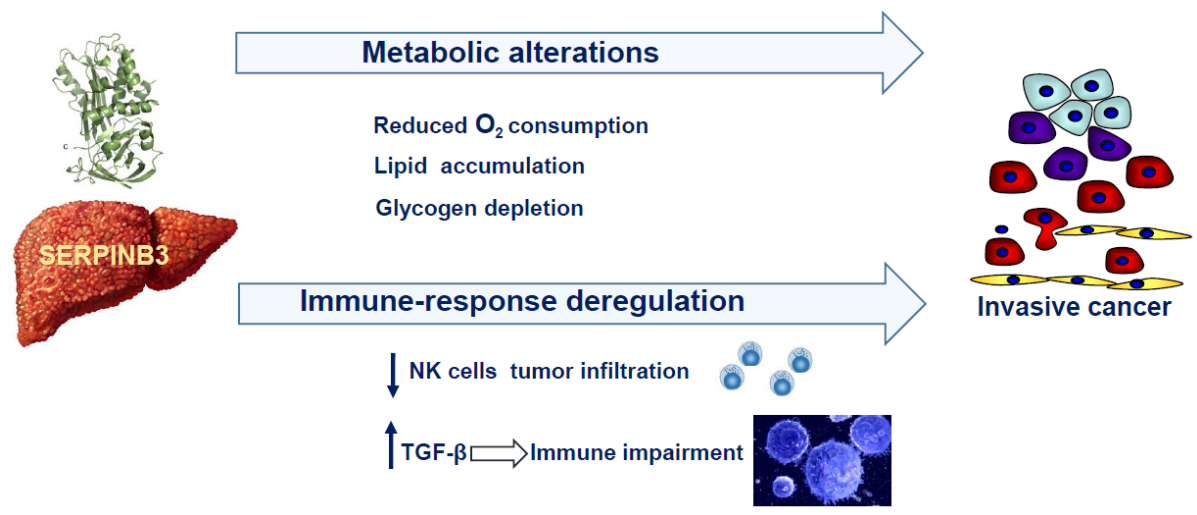

Figure 2. Biological activities determined by SerpinB3, with particular regard to metabolism and immune response modulation

mice transgenic for liver SerpinB3 showed higher liver regenerative ability compared to wild-type mice, supporting a role of this protein in promoting cell growth and proliferation ${ }^{[26]}$. Other mechanisms of tumor growth promotion induced by SerpinB3 include the up-regulation of Myc oncogene transcription with two different strategies ${ }^{[27]}$ : the first mechanism is through the intracellular SerpinB3 antiprotease activity that blocks its cleavage exerted by Calpain, preventing the generation of the non-oncogenic cytoplasmic Mycnick form and allowing nuclear translocation of Myc with pro-oncogenic activity. The second one consists in the transcriptional induction of Myc, through the increase of Yap pathway ${ }^{[27]}$. Furthermore, recent findings indicate that SerpinB3/SerpinB4 isoforms are a Ras-responsive factor that plays an important role in Rasassociated cytokine production and tumorigenesis ${ }^{[28]}$.

\section{Metabolic functions}

Recent findings indicate that SerpinB3 can determine metabolic alterations in the liver through the induction of dipeptidyl peptidase-4 (DPPIV/CD26), a transmembrane glycoprotein, that is increased in various malignant tumors, including HCC, and the expression of these two molecules was found positively correlated in HCCs and in the surrounding cirrhotic tissue ${ }^{[29]}$. Hepatoma cells overexpressing SerpinB3 showed increased DPPIV/CD26 levels and these features were associated with an increase in lipid droplet formation and with decreased glycogen deposition, typical features induced by DPPIV/CD26 ${ }^{[30-32]}$ [Figure 2]. These results are in agreement with previous findings, reporting remarkable lipid accumulation and glycogen depletion in the liver of SerpinB3-transgenic mice ${ }^{[33]}$. In addition, SerpinB3 was found overexpressed in human livers with $\mathrm{NASH}^{[34]}$, a condition at risk of $\mathrm{HCC}$ development. It is worth to note that SerpinB3 determined also a decreased oxygen consumption rate ${ }^{[29]}$, as a possible consequence of its physical interaction with mitochondrial respiratory complex I ${ }^{[24]}$.

\section{SerpinB3 in liver cancer}

In the liver SerpinB3 and its isoform SerpinB4, are undetectable in normal hepatocytes, but their expression progressively increases in chronic liver disease, in dysplastic nodules ${ }^{[35]}$ and in $\mathrm{HCC}^{[36,37]}$, suggesting their involvement in relatively early events of hepatocarcinogenesis ${ }^{[35]}$. SerpinB3 has also been detected in hepatoblastoma, the embryonal tumor of the liver, especially in the most aggressive forms, where a direct correlation was observed between its gene expression, the up-regulation of Myc oncogene and tumor extension ${ }^{[38]}$.

The presence of SerpinB3 has been further described in liver stem/progenitor cells positive for the hepatic epithelial cell adhesion molecule (EpCAM), both in human fetal livers and in adult livers with cirrhosis, and these findings were corroborated by the induction of this serpin in a mouse model of liver stem/progenitor cell activation ${ }^{[39]}$. Liver tumors with stemness signature are highly aggressive, and along this line the highest 
levels of SerpinB3 have been found overexpressed, together with TGF- $\beta 1$, in the subset of aggressive forms of hepatocellular carcinoma, characterized by early tumor recurrence after surgical resection ${ }^{[8]}$.

The tight correlation between SerpinB3 and TGF- $\beta$, that requires the integrity of the RSL of SerpinB3, as documented by in vitro studies ${ }^{[40]}$, has been also confirmed in non-tumor cirrhotic livers. The alterations of the microenvironment, characterized by the presence of chronic inflammation associated with liver fibrosis, typical features of the cirrhosis status, have been identified as a hallmark of liver carcinogenesis. In fact, more than $80 \%$ of the cases of hepatocellular carcinoma arise in livers with cirrhosis, a condition which constitute a real precancerous stage ${ }^{[41]}$. Activated hepatic stellate cells (HSC) represent key drivers of liver fibrosis and extracellular matrix (ECM) remodeling ${ }^{[42]}$, and a recent study has demonstrated that SerpinB3 is able to directly activate human HSC, resulting in a strong up-regulation of the expression of genes involved in fibrogenesis and angiogenesis ${ }^{[43]}$.

In recent years there is growing evidence that the impairment of immune surveillance plays a pivotal role in liver cancer development and progression ${ }^{[44]}$. In this context, TGF- $\beta$ is a key player, suppressing proper antitumor immune responses ${ }^{[44]}$, through the induction of regulatory $\mathrm{T}$ cells (Tregs) that have a profound ability to control immune responses ${ }^{[45,46]}$ and SerpinB3 might be also involved in the immune escape mechanism by enhancing TGF- $\beta$ production. Other findings through which SerpinB3 seems to promote the immune impairment are its ability to inhibit the intratumor infiltration by natural killer cells ${ }^{[4]}$ and to reduce the inflammatory response in other experimental settings ${ }^{[48]}$.

\section{Diagnostic and prognostic significance}

One of the most important and yet unmet needs in clinical settings is the availability of serological markers to identify patients with cirrhosis at higher risk of HCC development. Since the incidence of hepatocellular carcinoma in individuals with cirrhosis is $3 \%-5 \%$ per year ${ }^{[49]}$, the identification of the subgroup of patients with possible HCC development within the next few years would allow the development of a personalized clinical management and more effective early therapeutic interventions. On the basis of the oncogenic potential of SerpinB3, and of the reported findings of the presence of SERPINB3/4 isoforms (or SCCA) in the vast majority of HCCs specimens ${ }^{[36]}$, in the last years ELISA assays have been developed to assess the presence of SCCA as free protein and/or bound to IgM as circulating immune complexes in serum ${ }^{[50]}$. The occurrence of biomarker-IgM immune complexes has been described as the result of cancer immunoediting, in which natural IgMs are important players of the innate immune system preventing tumor formation ${ }^{[51]}$. Free SCCA is barely detectable in serum of patients with advanced liver disease and primary liver cancer, while this molecule was found coupled to IgMs (SCCA-IgM) in the majority of patients with HCC, whereas in the healthy control population their levels were below the limit of detection ${ }^{[50]}$.

\section{Patients with cirrhosis}

The concentration of circulating SCCA-IgM has been found progressively increased at different stages of liver disease, from chronic hepatitis to cirrhosis and HCC, reflecting the extent of SCCA protein overexpression in the liver ${ }^{[52]}$. In individual patients, the progressive increase of SCCA-IgM over time was remarkable in cirrhotic patients who developed HCC, and resulted unchanged in the majority of the cirrhotic patients without evidence of liver cancer during the same time interval ${ }^{[52]}$. These data have been confirmed in another retrospective study ${ }^{[53]}$, where baseline values of serological SCCA-IgM were nearly 4 -fold higher in patients who developed HCC than in those without HCC progression. In addition, SCCA-IgM values $\leq 200 \mathrm{AU} / \mathrm{mL}$ accurately identified patients at low risk of liver cancer in the subsequent year, with a negative predictive value of $97 \%{ }^{[53]}$.

In agreement with these findings, the prognostic role of this biomarker was confirmed in a prospective study showing that, among patients matched for clinical stage of cirrhosis, those with baseline levels of 
SCCA-IgM above the cut-off (200 AU/mL) developed more frequently HCC during follow-up than those negative for the biomarker ${ }^{[54]}$.

\section{Patients with HCC}

In a recent study that has retrospectively analyzed patients with cirrhosis and HCC, SCCA-IgM was proven efficient in the prediction of HCC prognosis, identifying HCC patients with long overall and progression-free

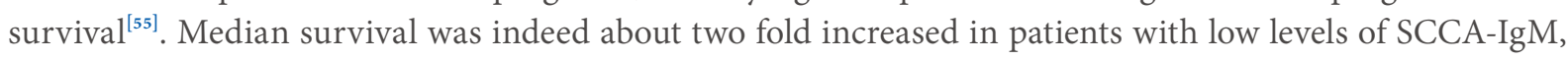
compared to those with elevated SCCA-IgM levels. At multivariate analysis tumour size and SCCA-IgM levels were identified as the only independent predictors of survival. In addition, levels of this biomarker were correlated with overall response to treatment, with a median time to progression that was more than doubled in patients with low SCCA-IgM levels ${ }^{[5]}$. The levels of the biomarker at four weeks were stable or increased in treated patients with stable disease or tumor, and were reduced in patients with complete response, while patients with partial response showed an intermediate behaviour. It is worth to note that in the same study, AFP was not able to predict complete response ${ }^{[55]}$. Another recent study addressed the behaviour of SCCA-IgM in patients with HCC who underwent locoregional therapy. Among the enrolled patients with a new diagnosis of HCC, SCCA-IgM levels at basal time and after one month of treatment, resulted significantly lower in patients who responded to therapy compared to those who did not respond ${ }^{[56]}$. These findings need to be confirmed in further studies, but are supported by a previous report that within the liver, HCCs with high SCCA-1 tissue expression have a poor prognosis and present higher rate of early recurrence after surgical resection ${ }^{[8]}$.

\section{FUTURE PERSPECTIVES}

Chronic inflammation and immune system play a crucial role in the development of dysplastic nodules and liver cancer ${ }^{[1,44]}$, as the pathogenesis of HCC has been associated with hepatocyte death, infiltration of inflammatory cells, and compensatory liver regeneration, which is dependent on the production of hepatic mitogenic cytokines produced by Kuppfer cells, such as IL- $6^{[57]}$. A previous study documented a positive correlation between RAS mutation, enhanced SerpinB3 and interleukin- 6 expression in samples of human colorectal and pancreatic tumors, reflecting an inflammatory response related to the nuclear factor kappalight chain enhancer of activated B cell ${ }^{[58]}$. Moreover, SerpinB3 was found physiologically expressed on the surface of $\mathrm{CD} 27+\mathrm{B}$ lymphocytes ${ }^{[59]}$, and it has been detected in peripheral blood mononuclear cells at transcript level both in cultured and in primary monocytes ${ }^{[60]}$. These findings suggest that SerpinB3 might play a role in the modulation of the immune response, favouring tumor development, but further studies are needed to clearly elucidate its role in this specific field.

\section{DECLARATIONS}

\section{Authors' contributions}

Drafted the article: Martini A

Revised the article and approved the version to be published: Pontisso P

\section{Availability of data and materials}

Not applicable.

\section{Financial support and sponsorship}

None.

\section{Conflicts of interest}

Both authors declare that there are no conflicts of interest. 


\section{Ethical approval and consent to participate}

Not applicable.

\section{Consent for publication}

Not applicable.

\section{Copyright}

(c) The Author(s) 2018.

\section{REFERENCES}

1. Forner A, Reig M, Bruix J. Hepatocellular carcinoma. Lancet 2018;391:13011314.

2. Valery PC, Laversanne M, Clark PJ, Petrick JL, McGlynn KA, Bray F. Projections of primary liver cancer to 2030 in 30 countries worldwide. Hepatology 2017; doi: 10.1002/hep.29498.

3. Calderaro J, Couchy G, Imbeaud S, Amaddeo G, Letouzé E, Blanc JF, Laurent C, Hajji Y, Azoulay D, Bioulac-Sage P, Nault JC, Zucman-Rossi J. Histological subtypes of hepatocellular carcinoma are related to gene mutations and molecular tumour classification. J Hepatol 2017;67:727-38.

4. Schulze K, Nault JC, Villanueva A. Genetic profiling of hepatocellular carcinoma using next-generation sequencing. J Hepatol 2016;65:1031-42.

5. Zucman-Rossi J, Villanueva A, Nault JC, Llovet JM. Genetic landscape and biomarkers of hepatocellular carcinoma. Gastroenterology 2015;149:1226-39.e4.

6. Hoshida Y, Nijman SM, Kobayashi M, Chan JA, Brunet JP, Chiang DY, Villanueva A, Newell P, Ikeda K, Hashimoto M, Watanabe G, Gabriel S, Friedman SL, Kumada H, Llovet JM, Golub TR. Integrative transcriptome analysis reveals common molecular subclasses of human hepatocellular carcinoma. Cancer Res 2009;69:7385-92.

7. Lee JS, Chu IS, Heo J, Calvisi DF, Sun Z, Roskams T, Durnez A, Demetris AJ, Thorgeirsson SS. Classification and prediction of survival in hepatocellular carcinoma by gene expression profiling. Hepatology 2004;40:667-76.

8. Turato C, Vitale A, Fasolato S, Ruvoletto M, Terrin L, Quarta S, Ramirez Morales R, Biasiolo A, Zanus G, Zali N, Tan PS, Hoshida Y, Gatta A, Cillo U, Pontisso P. SERPINB3 is associated with TGF-beta1 and cytoplasmic beta-catenin expression in hepatocellular carcinomas with poor prognosis. Br J Cancer 2014;110:2708-15.

9. Kato H, Torigoe T. Radioimmunoassay for tumor antigen of human cervical squamous cell carcinoma. Cancer 1977;40:1621-8.

10. Sun Y, Sheshadri N, Zong WX. SERPINB3 and B4: from biochemistry to biology. Semin Cell Dev Biol 2017;62:170-7.

11. Schick C, Brömme D, Bartuski AJ, Uemura Y, Schechter NM, Silverman GA. The reactive site loop of the serpin SCCA1 is essential for cysteine proteinase inhibition. Proc Natl Acad Sci U S A 1998;95:13465-70.

12. Schick C, Kamachi Y, Bartuski AJ, Cataltepe S, Schechter NM, Pemberton PA, Silverman GA. Squamous cell carcinoma antigen 2 is a novel serpin that inhibits the chymotrypsin-like proteinases cathepsin G and mast cell chymase. J Biol Chem 1997;272:1849-55.

13. Masumoto K, Sakata Y, Arima K, Nakao I, Izuhara K. Inhibitory mechanism of a cross-class serpin, the squamous cell carcinoma antigen 1. J Biol Chem 2003;278:45296-304.

14. Silverman GA, Bird PI, Carrell RW, Church FC, Coughlin PB, Gettins PG, Irving JA, Lomas DA, Luke CJ, Moyer RW, Pemberton PA, Remold-O’Donnell E, Salvesen GS, Travis J, Whisstock JC. The serpins are an expanding superfamily of structurally similar but functionally diverse proteins. Evolution, mechanism of inhibition, novel functions, and a revised nomenclature. J Biol Chem 2001;276:33293-6.

15. Kato H. Expression and function of squamous cell carcinoma antigen. Anticancer Res 1996;16:2149-53.

16. Cataltepe S, Gornstein ER, Schick C, Kamachi Y, Chatson K, Fries J, Silverman GA, Upton MP. Co-expression of the squamous cell carcinoma antigens 1 and 2 in normal adult human tissues and squamous cell carcinomas. J Histochem Cytochem 2000;48:113-22.

17. Takeda A, Kajiya A, Iwasawa A, Nakamura Y, Hibino T. Aberrant expression of serpin squamous cell carcinoma antigen 2 in human tumor tissues and cell lines: evidence of protection from tumor necrosis factor-mediated apoptosis. Biol Chem 2002;383:1231-6.

18. Cannito S, Turato C, Paternostro C, Biasiolo A, Colombatto S, Cambieri I, Quarta S, Novo E, Morello E, Villano G, Fasolato S, Musso T, David E, Tusa I, Rovida E, Autelli R, Smedile A, Cillo U, Pontisso P, Parola M. Hypoxia up-regulates SERPINB3 through HIF-2alpha in human liver cancer cells. Oncotarget 2015;6:2206-21.

19. Turato C, Kent P, Sebastiani G, Cannito S, Morello E, Terrin L, Biasiolo A, Simonato D, Parola M, Pantopoulos K, Pontisso P. Serpinb3 is overexpressed in the liver in presence of iron overload. J Investig Med 2018;66:32-8.

20. Suminami Y, Nagashima S, Vujanovic NL, Hirabayashi K, Kato H, Whiteside TL. Inhibition of apoptosis in human tumour cells by the tumour-associated serpin, SCC antigen-1. Br J Cancer 2000;82:981-9.

21. Vidalino L, Doria A, Quarta S, Zen M, Gatta A, Pontisso P. SERPINB3, apoptosis and autoimmunity. Autoimmun Rev 2009;9:108-12.

22. Katagiri C, Nakanishi J, Kadoya K, Hibino T. Serpin squamous cell carcinoma antigen inhibits UV-induced apoptosis via suppression of c-JUN NH2-terminal kinase. J Cell Biol 2006;172:983-90.

23. Murakami A, Suminami Y, Hirakawa H, Nawata S, Numa F, Kato H. Squamous cell carcinoma antigen suppresses radiation-induced cell death. Br J Cancer 2001;84:851-8. 
24. Ciscato F, Sciacovelli M, Villano G, Turato C, Bernardi P, Rasola A, Pontisso P. SERPINB3 protects from oxidative damage by chemotherapeutics through inhibition of mitochondrial respiratory complex I. Oncotarget 2014;5:2418-27.

25. Quarta S, Vidalino L, Turato C, Ruvoletto M, Calabrese F, Valente M, Cannito S, Fassina G, Parola M, Gatta A, Pontisso P. SERPINB3 induces epithelial-mesenchymal transition. J Pathol 2010;221:343-56.

26. Villano G, Quarta S, Ruvoletto MG, Turato C, Vidalino L, Biasiolo A, Tono N, Lunardi F, Calabrese F, Dall'olmo L, Dedja A, Fassina G, Gatta A, Pontisso P. Role of squamous cell carcinoma antigen-1 on liver cells after partial hepatectomy in transgenic mice. Int J Mol Med 2010;25:137-43.

27. Turato C, Cannito S, Simonato D, Villano G, Morello E, Terrin L, Quarta S, Biasiolo A, Ruvoletto M, Martini A, Fasolato S, Zanus G, Cillo U, Gatta A, Parola M, Pontisso P. SerpinB3 and Yap interplay increases Myc oncogenic activity. Sci Rep 2015;5:17701.

28. Catanzaro JM, Sheshadri N, Pan JA, Sun Y, Shi C, Li J, Powers RS, Crawford HC, Zong WX. Oncogenic Ras induces inflammatory cytokine production by upregulating the squamous cell carcinoma antigens SerpinB3/B4. Nat Commun 2014;5:3729.

29. Fasolato S, Trevellin E, Ruvoletto M, Granzotto M, Zanus G, Boscaro E, Babetto E, Terrin L, Battocchio MA, Ciscato F, Turato C, Quarta S, Cillo U, Pontisso P, Vettor R. SerpinB3 induces dipeptidyl-peptidase IV/CD26 expression and its metabolic effects in hepatocellular carcinoma. Life Sci 2018;200:134-41.

30. Shirakawa J, Fujii H, Ohnuma K, Sato K, Ito Y, Kaji M, Sasaki H, Nagashima Y, Amo K, Aoki K, Morimoto C, Takeda E, Terauchi Y. Dietinduced adipose tissue inflammation and liver steatosis are prevented by DPP-4 inhibition in diabetic mice. Diabetes 2011;60:1246-57.

31. Akarte AS, Srinivasan BP, Gandhi S, Sole S. Chronic DPP-IV inhibition with PKF-275-055 attenuates inflammation and improves gene expressions responsible for insulin secretion in streptozotocin induced diabetic rats. Eur J Pharm Sci 2012;47:456-63.

32. Blaslov K, Bulum T, Zibar K, Duvnjak L. Incretin based therapies: a novel treatment approach for non-alcoholic fatty liver disease. World J Gastroenterol 2014;20:7356-65.

33. Villano G, Ruvoletto M, Ceolotto G, Quarta S, Calabrese F, Turato C, Tono N, Crescenzi M, Biasiolo A, Cattelan A, Merkel C, Avogaro A, Gatta A, Pontisso P. SERPINB3 is associated with longer survival in transgenic mice. Sci Rep 2013;3:3056.

34. Martini A, Fattovich G, Guido M, Bugianesi E, Biasiolo A, Ieluzzi D, Gallotta A, Fassina G, Merkel C, Gatta A, Negro F, Pontisso P. HCV genotype 3 and squamous cell carcinoma antigen (SCCA)-IgM are independently associated with histological features of NASH in HCV-infected patients. J Viral Hepat. 2015;22:800-8.

35. Guido M, Roskams T, Pontisso P, Fassan M, Thung SN, Giacomelli L, Sergio A, Farinati F, Cillo U, Rugge M. Squamous cell carcinoma antigen in human liver carcinogenesis. J Clin Pathol 2008;61:445-7.

36. Pontisso P, Calabrese F, Benvegnu L, Lise M, Belluco C, Ruvoletto MG, Marino M, Valente M, Nitti D, Gatta A, Fassina G. Overexpression of squamous cell carcinoma antigen variants in hepatocellular carcinoma. Br J Cancer 2004;90:833-7.

37. Trerotoli P, Fransvea E, Angelotti U, Antonaci G, Lupo L, Mazzocca A, Mangia A, Antonaci S, Giannelli G. Tissue expression of Squamous Cellular Carcinoma Antigen (SCCA) is inversely correlated to tumor size in HCC. Mol Cancer 2009;8:29.

38. Turato C, Buendia MA, Fabre M, Redon MJ, Branchereau S, Quarta S, Ruvoletto M, Perilongo G, Grotzer MA, Gatta A, Pontisso P. Over-expression of SERPINB3 in hepatoblastoma: a possible insight into the genesis of this tumour? Eur J Cancer 2012;48:1219-26.

39. Villano G, Turato C, Quarta S, Ruvoletto M, Ciscato F, Terrin L, Semeraro R, Paternostro C, Parola M, Alvaro D, Bernardi P, Gatta A, Pontisso P. Hepatic progenitor cells express SerpinB3. BMC Cell Biol 2014;15:5.

40. Turato C, Calabrese F, Biasiolo A, Quarta S, Ruvoletto M, Tono N, Paccagnella D, Fassina G, Merkel C, Harrison TJ, Gatta A, Pontisso P. SERPINB3 modulates TGF-beta expression in chronic liver disease. Lab Invest 2010;90:1016-23.

41. Hernandez-Gea V, Toffanin S, Friedman SL, Llovet JM. Role of the microenvironment in the pathogenesis and treatment of hepatocellular carcinoma. Gastroenterology 2013;144:512-27.

42. Friedman SL. Hepatic stellate cells: protean, multifunctional, and enigmatic cells of the liver. Physiol Rev 2008;88:125-72.

43. Novo E, Villano G, Turato C, Cannito S, Paternostro C, Busletta C, Biasiolo A, Quarta S, Morello E, Bocca C, Miglietta A, David E, Sutti S, Plebani M, Albano E, Parola M, Pontisso P. SerpinB3 promotes pro-fibrogenic responses in activated hepatic stellate cells. Sci Rep 2017;7:3420-3.

44. Ringelhan M, Pfister D, O’Connor T, Pikarsky E, Heikenwalder M. The immunology of hepatocellular carcinoma. Nat Immunol 2018;19:222-32.

45. Roth GS, Decaens T. Liver immunotolerance and hepatocellular carcinoma: patho-physiological mechanisms and therapeutic perspectives. Eur J Cancer 2017;87:101-12.

46. Carambia A, Freund B, Schwinge D, Heine M, Laschtowitz A, Huber S, Wraith DC, Korn T, Schramm C, Lohse AW, Heeren J, Herkel J. TGF- $\beta$-dependent induction of CD4+CD25+Foxp3+ Tregs by liver sinusoidal endothelial cells. J Hepatol 2014;61:594-9.

47. Suminami Y, Nagashima S, Murakami A, Nawata S, Gondo T, Hirakawa H, Numa F, Silverman GA, Kato H. Suppression of a squamous cell carcinoma (SCC)-related serpin, SCC antigen, inhibits tumor growth with increased intratumor infiltration of natural killer cells. Cancer Res 2001;61:1776-80.

48. Lunardi F, Villano G, Perissinotto E, Agostini C, Rea F, Gnoato M, Bradaschia A, Valente M, Pontisso P, Calabrese F. Overexpression of SERPIN B3 promotes epithelial proliferation and lung fibrosis in mice. Lab Invest 2011;91:945-54.

49. Fattovich G, Giustina G, Degos F, Tremolada F, Diodati G, Almasio P, Nevens F, Solinas A, Mura D, Brouwer JT, Thomas H, Njapoum C, Casarin C, Bonetti P, Fuschi P, Basho J, Tocco A, Bhalla A, Galassini R, Noventa F, Schalm SW, Realdi G. Morbidity and mortality in compensated cirrhosis type C: a retrospective follow-up study of 384 patients. Gastroenterology 1997;112:463-72.

50. Beneduce L, Castaldi F, Marino M, Quarta S, Ruvoletto M, Benvegnù L, Calabrese F, Gatta A, Pontisso P, Fassina G. Squamous cell carcinoma antigen-immunoglobulin M complexes as novel biomarkers for hepatocellular carcinoma. Cancer 2005;103:2558-65.

51. Rubin B. Natural immunity has significant impact on immune responses against cancer. Scand J Immunol 2009;69:275-90. 
52. Pontisso P, Quarta S, Caberlotto C, Beneduce L, Marino M, Bernardinello E, Tono N, Fassina G, Cavalletto L, Gatta A, Chemello L. Progressive increase of SCCA-IgM immune complexes in cirrhotic patients is associated with development of hepatocellular carcinoma. Int J Cancer 2006;119:735-40.

53. Buccione D, Fatti G, Gallotta A, Loggi E, Di Donato R, Testa L, Saitta C, Santi V, Di Micoli A, Fazio V, Picciotto A, Biasiolo A. F-9 Serum SCCA-IgM as a predictor of hepatocellular carcinoma (HCC) in patients with liver cirrhosis. Open J Gastroenterol 2011;2:56-61.

54. Biasiolo A, Trotta E, Fasolato S, Ruvoletto M, Martini A, Gallotta A, Fassina G, Angeli P, Gatta A, Pontisso P. Squamous cell carcinoma antigen-IgM is associated with hepatocellular carcinoma in patients with cirrhosis: a prospective study. Dig Liver Dis 2016;48:197-202.

55. Pozzan C, Cardin R, Piciocchi M, Cazzagon N, Maddalo G, Vanin V, Giacomin A, Pontisso P, Cillo U, Farinati F. Diagnostic and prognostic role of SCCA-IgM serum levels in hepatocellular carcinoma (HCC). J Gastroenterol Hepatol 2014;29:1637-44.

56. Guarino M, Di Costanzo GG, Gallotta A, Tortora R, Paneghetti L, Auriemma F, Tuccillo C, Fassina G, Caporaso N, Morisco F. Circulating SCCA-IgM complex is a useful biomarker to predict the outcome of therapy in hepatocellular carcinoma patients. Scand J Clin Lab Invest 2017;77:448-53.

57. Sica A, Invernizzi P, Mantovani A. Macrophage plasticity and polarization in liver homeostasis and pathology. Hepatology 2014;59:2034-42.

58. Sheshadri N, Catanzaro JM, Bott AJ, Sun Y, Ullman E, Chen EI, Pan JA, Wu S, Crawford HC, Zhang J, Zong WX. SCCA1/SERPINB3 promotes oncogenesis and epithelial-mesenchymal transition via the unfolded protein response and IL6 signaling. Cancer Res 2014;74:6318-29.

59. Vidalino L, Doria A, Quarta SM, Crescenzi M, Ruvoletto M, Frezzato F, Trentin L, Turato C, Parolin MC, Ghirardello A, Iaccarino L, Cavalletto L, Chemello L, Gatta A, Pontisso P. SERPINB3 expression on B-cell surface in autoimmune diseases and hepatitis C virusrelated chronic liver infection. Exp Biol Med 2012;237:793-802.

60. Chechlinska M, Kowalewska M, Brzoska-Wojtowicz E, Radziszewski J, Ptaszynski K, Rys J, Kaminska J, Nowak R. Squamous cell carcinoma antigen 1 and 2 expression in cultured normal peripheral blood mononuclear cells and in vulvar squamous cell carcinoma. Tumour Biol 2010;31:559-67. 